\title{
Effect of Workplace Noise on Hearing Ability in Tile and Ceramic Industry Workers in Iran: A 2-Year Follow-Up Study
}

\author{
Mehrdad Mostaghaci, ${ }^{1}$ Seyyed Jalil Mirmohammadi, ${ }^{1}$ Amir Houshang Mehrparvar, \\ Maryam Bahaloo, ${ }^{2}$ Abolfazl Mollasadeghi, ${ }^{1}$ and Mohammad Hossein Davari ${ }^{1}$ \\ ${ }^{1}$ Department of Occupational Medicine, School of Medicine, Shahid Sadoughi University of Medical Sciences, \\ Shahid Rahnemoun Hospital, Farrokhi Avenue, Yazd 89138-14389, Iran \\ ${ }^{2}$ Industrial Disease Research Center, Shahid Sadoughi University of Medical Sciences, Shahid Rahnemoun Hospital, \\ Farrokhi Avenue, Yazd 89138-14389, Iran
}

Correspondence should be addressed to Maryam Bahaloo; drbahaloo@gmail.com

Received 30 August 2013; Accepted 30 September 2013

Academic Editors: R. Pohjanvirta and J.-M. Sabatier

Copyright (C) 2013 Mehrdad Mostaghaci et al. This is an open access article distributed under the Creative Commons Attribution License, which permits unrestricted use, distribution, and reproduction in any medium, provided the original work is properly cited.

Introduction. Noise as a common physical hazard may lead to noise-induced hearing loss, an irreversible but preventable disorder. Annual audiometric evaluations help detect changes in hearing status before clinically significant hearing loss develops. This study was designed to track hearing threshold changes during 2-year follow-up among tile and ceramic workers. Methods. This followup study was conducted on 555 workers (totally 1110 ears). Subjects were divided into four groups according to the level of noise exposure. Hearing threshold in conventional audiometric frequencies was measured and standard threshold shift was calculated for each ear. Results. Hearing threshold was increased during 2 years of follow-up. Increased hearing threshold was most frequently observed at 4000, 6000, and $3000 \mathrm{~Hz}$. Standard threshold shift was observed in 13 (2.34\%), 49 (8.83\%), 22 (3.96\%), and 63 (11.35\%) subjects in the first and second years of follow-up in the right and left ears, respectively. Conclusions. This study has documented a high incidence of noise-induced hearing loss in tile and ceramic workers that would put stress on the importance of using hearing protection devices.

\section{Introduction}

Noise is the most common physical hazard in the industrial workplaces. A report from the European Union mentions that about $28 \%$ of workers are exposed to noise level approximately between 85 and $90 \mathrm{dBA}$ [1]. The most common health problem due to exposure to noise is noise-induced hearing loss (NIHL), an irreversible but preventable disorder [2]. NIHL is the second most common form of acquired hearing loss, after presbycusis $[3,4]$, and is a major concern for workers' health in different countries [4-6].

In the industrial settings, when noise exceeds permissible levels, hearing conservation program should be started, which contains hearing evaluation and some other activities.

In 1996 National Institute of Occupational Safety and Health (NIOSH) reported that about 30 million workers in
USA are exposed to loud noise which can lead to hearing loss [7]. It is estimated that 10 million workers suffer from NIHL in USA [8].

NIHL is typically a bilateral and symmetric hearing loss with a notch of the audiogram at 3,4 , or $6 \mathrm{kHz}$ and a recovery at $8 \mathrm{kHz}$ as the first sign [4]. This hearing impairment may be aggravated if exposure to noise is continued $[9,10]$.

Prevention of deafness and hearing impairment (PDH), a WHO program, is especially planned for developing countries due to lack of accurate population-based studies about the prevalence and causes of deafness and hearing loss [1113]. Occupational Safety and Health Administration (OSHA) requires that all workers exposed to noise more than $85 \mathrm{dBA}$ be screened for NIHL annually [14].

Standard threshold shift (STS) is defined as a $10 \mathrm{~dB}$ or more change in average hearing threshold at 2000,3000, and 
$4000 \mathrm{~Hz}$. So, even if the audiogram is not abnormal, positive STS is important to find those workers susceptible to hazardous effects of noise on hearing $[2,3,15]$.

Annual audiometric evaluations help detect changes in hearing status before clinically significant hearing loss develops [16]. Recently, other methods such as extended highfrequency audiometry and otoacoustic emissions are introduced for early diagnosis of NIHL $[17,18]$.

Hong found a prevalence of $60 \%$ for hearing loss among construction workers which was directly related to work experience. They found left ear to be more sensitive to noise. Workers who used hearing protection devices (HPDs) showed lower frequency of hearing loss than others. They did not find a typical notch at 4 or $6 \mathrm{kHz}$ [4].

In a large study in The Netherlands they assessed the effect of duration of noise and noise level on the frequency of NIHL and found that duration of exposure is more important in NIHL causation than noise level [10]. In another study in a steel rolling mill they found that $56.8 \%$ of workers in their worse ear and $28.2 \%$ in their better ear suffered from hearing loss and noise level was between 49 and 93 dBA [19].

Other studies in different parts of the world have assessed occupational hearing loss in different industries (Morata et al. 1997 in printing industry [20], Bhattacharya et al. 1990 in a pharmaceutical company [21], and Shaikh 1996 in a polyester fiber plant [22]).

In the tile and ceramic industry, because of some machinery, equipment, and tools, hazardous noise is frequently observed. Tile and ceramic industry is one of the main industries in Iran, and Yazd, a central province, owns the largest numbers of tile and ceramic producing factories in which workers are subject to NIHL. We could not find a study on NIHL in tile and ceramic industry. So this study was designed to track hearing threshold changes during 2 years of followup among tile and ceramic workers.

\section{Materials and Methods}

This was a follow-up study conducted on 594 workers from 5 tile and ceramic factories in Yazd, a central province of Iran. Factories were selected by simple random sampling from all tile and ceramic factories in Yazd $(n=29)$. In each factory subjects were selected by simple random sampling from different jobs. Each factory had 14 different job titles including glazing, glaze-making, forming, ball mill, spray drying, mixing and grinding, packing and loading, mechanic, forklift driving, warehouse, firing, printing, service, and office. These 14 subgroups were merged to produce 4 major groups according to noise level. Group 1 (noise level $=75-92 \mathrm{dBA}, 8 \mathrm{~h}$ time-weighted average $(\mathrm{TWA})=86.4 \mathrm{dBA}$ ) includes glazing, glaze-making, forming, packing and loading, forklift driving, firing, printing, and service; group 2 (noise level $=85-$ $101 \mathrm{dBA}, 8 \mathrm{~h}-\mathrm{TWA}=92.6 \mathrm{dBA}$ ) includes mixing and grinding, ball mill, and spray drying; group 3 (noise level: 65-101 dBA, $8 \mathrm{~h}$-TWA $=82.3 \mathrm{dBA}$ ) includes mechanics; and control group (noise level: lower than $75 \mathrm{dBA}$ ) includes warehouse and office workers.

Those with previous history of acoustic trauma, congenital hearing loss, and ototoxic drug consumption and age more than 50 years were excluded from the study. The workers irregularly used hearing conservation devices (ear plugs).

Noise level was extracted from the result of measurements routinely performed in the factories by industrial hygiene incorporations and was presented as time-weighted average (TWA) for an eight-hour shift.

Audiometry was performed for the subjects (using clinical audiometer: AC40, Interacoustic, Denmark, headphone: TDH39) in an acoustic chamber meeting the criteria of ANSI 2004 [23] after at least 16 hours abstinence from noise. The audiologist who performed the tests (baseline and followup tests) was the same. Hearing threshold in conventional audiometric frequencies (i.e., 250, 500, 1000, 2000, 3000, 4000,6000 , and $8000 \mathrm{~Hz}$ ) was measured. Frequencies of 3000,4000 , and $6000 \mathrm{~Hz}$ were considered as the frequencies with the highest susceptibility to noise so the mean change $(10 \mathrm{~dB}$ or more increase in the hearing threshold at these frequencies) was calculated for each job category. STS was calculated for each ear as well. Hearing loss at each frequency was defined as hearing threshold higher than $20 \mathrm{~dB}$. During follow-up, 39 subjects changed their job so were not available for follow-up.

Data was analyzed by SPSS (ver. 18) using Student's $t$-test, chi-square test, and ANOVA. A $P$ value of less than 0.05 was taken as the level of significance. An informed consent was obtained from each participant. This study was approved by the ethics committee of Shahid Sadoughi University of Medical Sciences.

\section{Results}

After considering exclusion criteria and subjects who were lost from follow-up, 555 tile and ceramic workers entered the study (totally 1110 ears). Table 1 shows demographic data of all workers in each job category.

Mean hearing threshold was measured at each audiometric frequency. Figure 1 compares the mean hearing threshold at different frequencies in each ear. Table 2 shows the prevalence of abnormal threshold $(>20 \mathrm{~dB})$ in different frequencies among different job categories. Mean threshold change at 3000, 4000, and $6000 \mathrm{~Hz}$ was calculated for each job category which is presented in Table 3.

Percentage of abnormal threshold in different frequencies in each ear is shown in Figure 2.

A number of subjects showed STS after first and second year of follow-up. STS was observed in 13 (2.34\%) and 49 $(8.83 \%)$ subjects in the first and second years of follow-up in the right ear and in $22(3.96 \%)$ and 63 (11.35\%) subjects in the first and second years of follow-up in the left ear.

\section{Discussion}

Noise as a common physical exposure in many industrial workplaces may lead to various health effects, especially NIHL. In this study we evaluated hearing threshold shift in a 2-year follow-up among tile and ceramic workers. The population which we studied was a young population with exposure to continuous noise during their eight hour 
TABLE 1: Demographic properties of all workers in each job category.

\begin{tabular}{|c|c|c|c|c|}
\hline & Group & Mean & $\mathrm{SD}$ & $P$ value \\
\hline \multirow{4}{*}{ Age (year) } & Control & 33.50 & 7.34 & \multirow{4}{*}{0.719} \\
\hline & 1 & 33.50 & 6.70 & \\
\hline & 2 & 32.66 & 7.06 & \\
\hline & 3 & 33.99 & 6.91 & \\
\hline \multirow{4}{*}{ Work experience (year) } & Control & 7.94 & 4.46 & \multirow{4}{*}{0.668} \\
\hline & 1 & 7.91 & 3.83 & \\
\hline & 2 & 8.33 & 3.85 & \\
\hline & 3 & 8.45 & 3.68 & \\
\hline \multirow{4}{*}{ Height $(\mathrm{cm})$} & Control & 172.23 & 8.81 & \multirow{4}{*}{0.110} \\
\hline & 1 & 173.55 & 6.76 & \\
\hline & 2 & 174.98 & 5.44 & \\
\hline & 3 & 175.14 & 5.47 & \\
\hline \multirow{4}{*}{ Weight (Kg) } & Control & 74.16 & 11.02 & \multirow{4}{*}{0.194} \\
\hline & 1 & 76.72 & 14.09 & \\
\hline & 2 & 79.08 & 12.35 & \\
\hline & 3 & 78.05 & 12.91 & \\
\hline
\end{tabular}

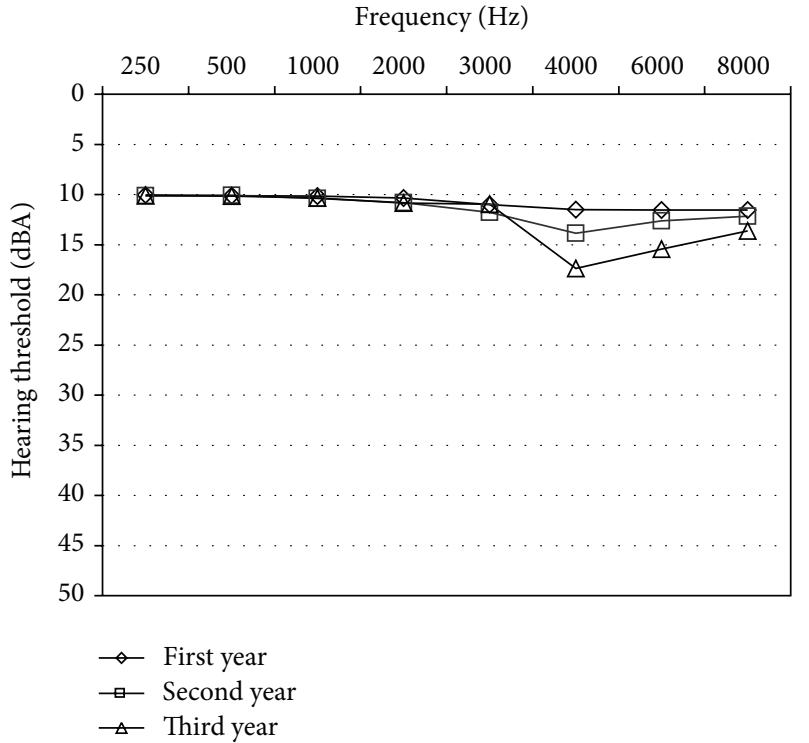

(a) Right ear

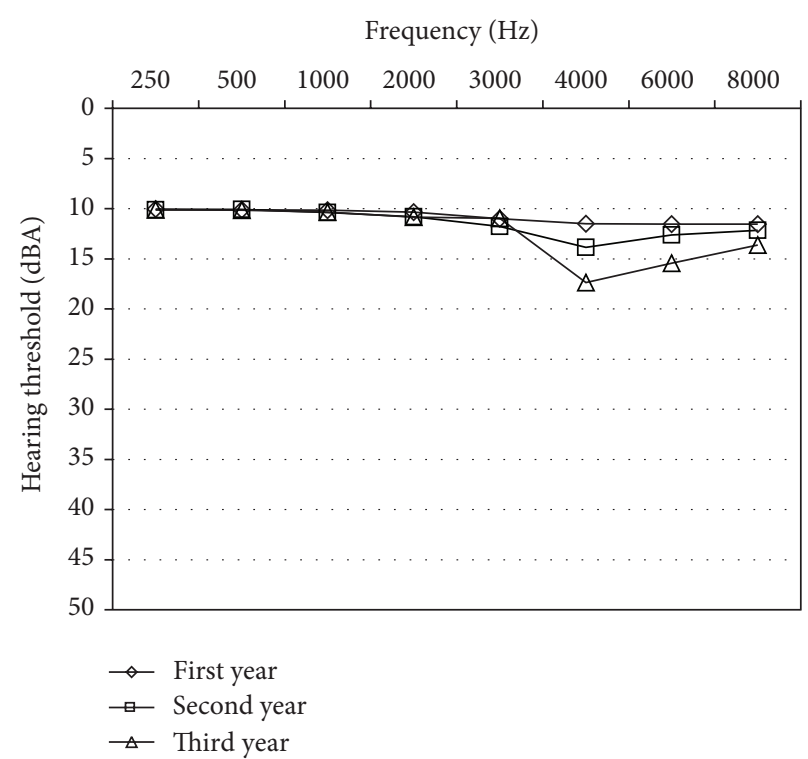

(b) Left ear

FIGURE 1: Trend of hearing threshold change in right and left ears in different years of evaluation among all subjects.

work shift. Most workers in different parts of tile factories are exposed to noise level higher than ACGIH (American Conference on Governmental Industrial Hygienists) TLV (Threshold Limit Value), that is, $85 \mathrm{dBA}$. The exposure to noise was not significantly changed during two years of follow-up. To the best of knowledge, this was the first followup study for finding hearing loss trends in tile workers in our country. In other countries we could not find similar studies on tile and ceramic workers.

In the factories which were evaluated in this study, Hearing Conservation Program (HCP) according to OSHA is installed but not completely, so annual noise monitoring and annual audiometric tests are mandatory for the workers, but hearing conservation devices are not used regularly and workers are not trained accordingly [24]. The use of HPD was recorded according to the workers' self-report which is not reliable [25-27].

How the workers used HPD is also another important factor that affects the true exposure to noise which could not be evaluated in this study $[28,29]$.

In this study, the workers were categorized according to the exposure to noise which was evaluated environmentally, so the real exposure of each worker is probably different from that of another worker in the same job [30]. 


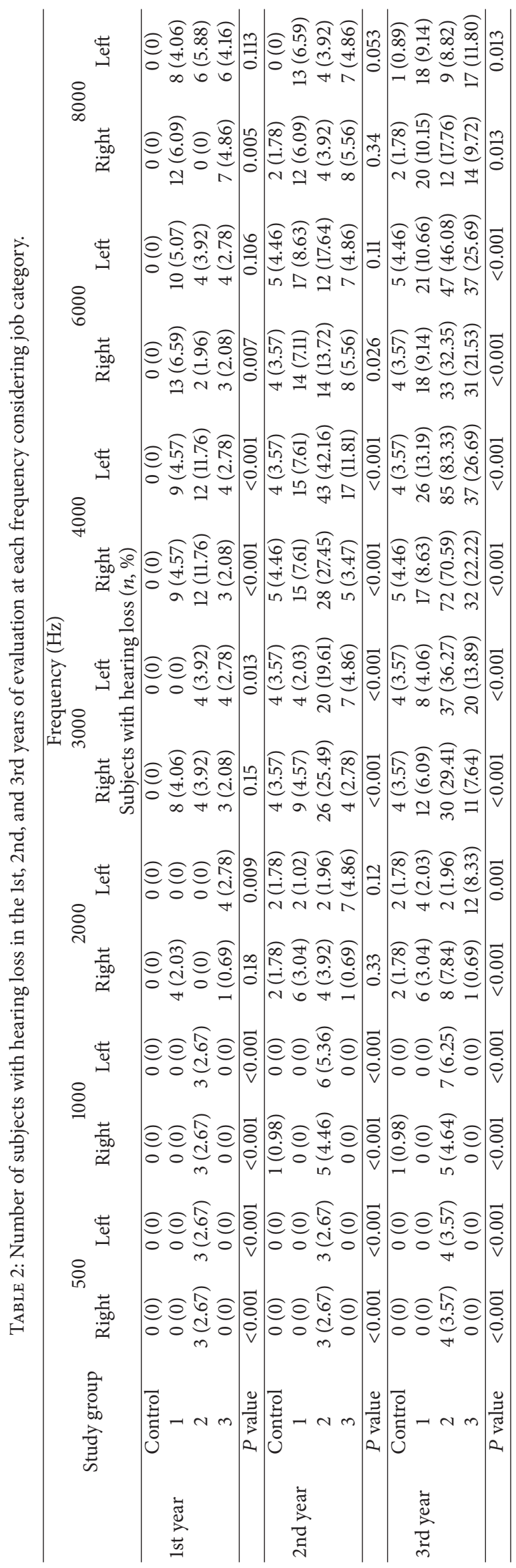


Table 3: Prevalence of mean threshold change at 3000, 4000, and $6000 \mathrm{~Hz}$ in each job category.

\begin{tabular}{|c|c|c|c|c|c|}
\hline \multirow{3}{*}{ Job category } & \multirow{3}{*}{ Follow-up year } & \multicolumn{4}{|c|}{ Threshold change } \\
\hline & & \multicolumn{2}{|c|}{ Negative } & \multicolumn{2}{|c|}{ Positive } \\
\hline & & Number & Percent & Number & Percent \\
\hline \multirow{2}{*}{ Control } & 1 st & 108 & 96.43 & 4 & 3.57 \\
\hline & 2nd & 110 & 98.21 & 2 & 1.79 \\
\hline \multirow{2}{*}{1} & 1st & 181 & 91.88 & 16 & 8.12 \\
\hline & 2nd & 148 & 75.13 & 49 & 24.87 \\
\hline \multirow{2}{*}{2} & 1st & 129 & 89.58 & 15 & 10.42 \\
\hline & 2nd & 93 & 64.57 & 51 & 35.43 \\
\hline \multirow{2}{*}{3} & 1st & 96 & 94.12 & 6 & 5.88 \\
\hline & 2nd & 87 & 85.29 & 15 & 14.71 \\
\hline
\end{tabular}

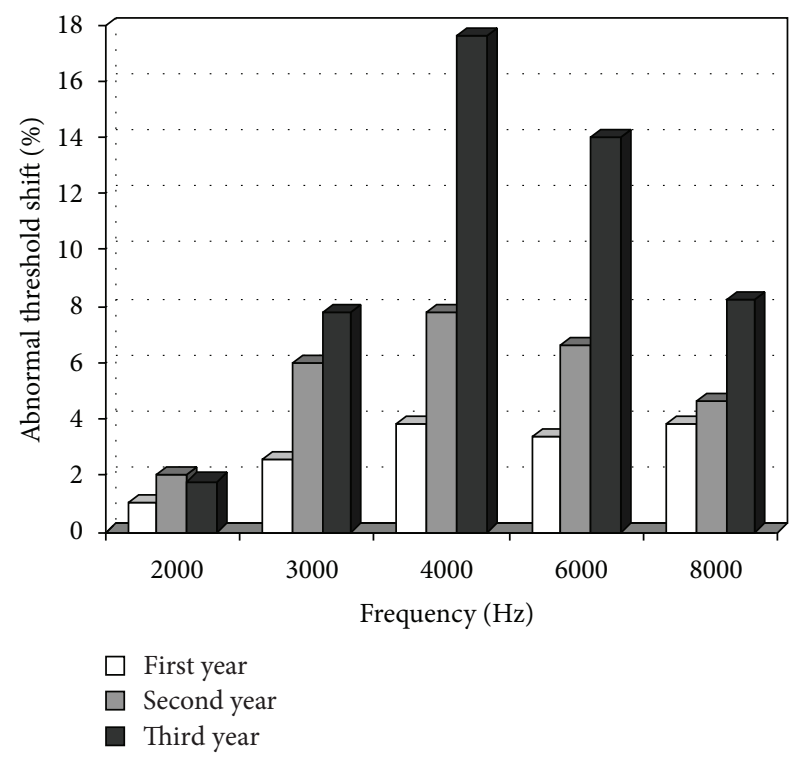

(a) Right ear

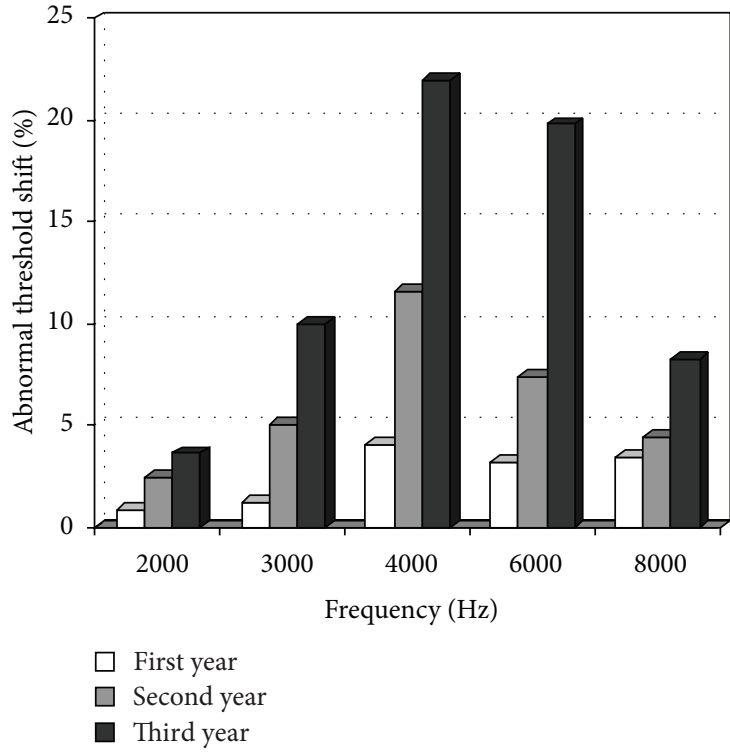

(b) Left ear

FIGURE 2: Percentage of abnormal hearing threshold $(>20 \mathrm{~dB})$ in different frequencies in right and left ears in different years of follow-up.

In the current study, although the mean hearing thresholds at all frequencies were in the normal range, a considerable number of workers suffered from NIHL, and its frequency was significantly increased during the followup period (after 2 years). We found that hearing loss was significantly higher in the workers exposed to noise than in the control group consistent with the findings of Neitzel et al. [31] and Ologe et al. [19], Leensen et al. [10], Ahmed et al. [32], Osibogun et al. [33], and Shakhatreh et al. [34]. We found the highest frequency of threshold change in the workers with the highest exposure to noise who were working in mixing, grinding, and ball mill.

Hearing loss was most commonly seen at $4000 \mathrm{~Hz}$ consistent with many other previous studies [4]. $6000 \mathrm{~Hz}$ and $3000 \mathrm{~Hz}$ were the second and third frequencies affected which is typical for NIHL to affect frequencies higher than $3000 \mathrm{~Hz}$ $[4,10]$. So in most cases of NIHL, the affected people are not aware of their impairment, because low audiometric frequencies are much more important for daily conversation $[4,35]$.

Low audiometric frequencies were affected in a few subjects. It is known that low audiometric frequencies are less susceptible to noise and are affected later than high frequencies, and our study subjects were mostly young persons with work experience less than 15 years. We found that the hearing threshold was clearly increased during follow-up time at these frequencies and lower frequencies were approximately intact even after 2 years of follow-up. We found a higher prevalence of hearing loss in left ear than right ear consistent with Hong [4], Ross et al. [15], Marvel et al. [36], Pirila et al. [37], and Simpson et al. [38], although the exact mechanism of higher involvement of left ear is not understood yet.

We found that about $3 \%$ and $10 \%$ of subjects suffered from STS after 1 and 2 years follow-up, respectively. The change in mean threshold of 3000, 4000, and $6000 \mathrm{~Hz}$ (frequencies most affected by noise) was significantly higher than STS 
which is measured by the change in mean threshold of 2000 , 3000 , and $4000 \mathrm{~Hz}$.

One of the typical early signs of NIHL is a V-shaped notch which is mostly seen at the most sensitive frequencies to noise (i.e., 3000,4000 , or $6000 \mathrm{~Hz}$ ) [39]. We found this typical notch in a considerable number of workers but Hong who evaluated NIHL among construction workers did not find this sign [4].

This study had some limitations: some workers were transformed to another job inside the factory during followup period, but we assessed them as the members of the previous job. The number of female workers was low so we could not compare the results between males and females. There were 14 job titles in the factories, but in order to analyze the data we assessed them in four groups, so the workers in each group were exposed to a range of noise level. The workers used HPDs irregularly, so we could not analyze the data regarding HPDs use.

\section{Conclusion}

This study showed a high frequency of hearing loss in tile and ceramic workers in spite of the obligation by health systems to install hearing conservation program.

\section{Conflict of Interests}

The authors declare that there is no conflict of interests that would prejudice the impartiality of this work.

\section{References}

[1] European Agency for Safety and Health at Work (EASHW), Monitoring the State of Occupational Safety and Health in the European Union Pilot Study, 2000.

[2] D. E. Dunn and P. M. Robinowitz, "Noise," in Textbook of Clinical Occupational and Environmental Medicine, L. Rosenstock, Ed., p. 893, Elsevier Saunders, Philadelphia, Pa, USA, 2nd edition, 2005.

[3] P. M. Robinowitz and T. S. Rees, "Occupational hearing loss," in Clinical Occupational and Environmental Medicine, L. Rosenstock, Ed., pp. 426-430, Elsevier Saunders, Philadelphia, Pa, USA, 2nd edition, 2005.

[4] O. Hong, "Hearing loss among operating engineers in American construction industry," International Archives of Occupational and Environmental Health, vol. 78, no. 7, pp. 565-574, 2005.

[5] J.-D. Chen and J.-Y. Tsai, "Hearing loss among workers at an oil refinery in Taiwan," Archives of Environmental Health, vol. 58, no. 1, pp. 55-58, 2003.

[6] D. I. McBride, H. M. Firth, and G. P. Herbison, "Noise exposure and hearing loss in agriculture: a survey of farmers and farm workers in the Southland region of New Zealand," Journal of Occupational and Environmental Medicine, vol. 45, no. 12, pp. 1281-1288, 2003.

[7] National Institute for Occupational Safety and Health (NIOSH), Criteria for a Recommended Standard, Noise Exposure-Revised Criteria, US Department of Health and Human Services, Public Health Service, Center for Disease Control and Prevention, Washington, DC, USA, 1996.
[8] U.S. Department of Labor, Occupational Safety and Health Administration (USDOL OSHA), "Noise and Hearing Conservation," 2002, https://www.osha.gov/SLTC/noisehearingconservation/.

[9] G. Rösler, "Progression of hearing loss caused by occupational noise," Scandinavian Audiology, vol. 23, pp. 13-37, 1994.

[10] M. C. J. Leensen, J. C. Van Duivenbooden, and W. A. Dreschler, "A retrospective analysis of noise-induced hearing loss in the Dutch construction industry," International Archives of Occupational and Environmental Health, vol. 84, no. 5, pp. 577-590, 2011.

[11] A. W. Smith, "The World Health Organisation and the prevention of deafness and hearing impairment caused by noise," Noise Health, vol. 1, no. 1, pp. 6-12, 1998.

[12] World Health Organisation, "Prevention of noise induced hearing loss," Report of a WHO-PDH informal consultation, No 3 in the series, Strategies for prevention of deafness and hearing impairment, WHO-PDH-98.5, 1997.

[13] T. M. Akande and F. E. Ologe, "Noise induced hearing loss (NIHL) in the middle belt of Nigeria," Postgraduate Doctor Africa, vol. 25, no. 4, pp. 81-82, 2003.

[14] US Department of Labor (USDL), Occupational Safety and Health Administration (OSHA), "Occupational noise exposure, hearing conservation amendment, final rule," Federal Register, vol. 48, pp. 9738-9785, 1983.

[15] J. A. S. Ross, J. I. Macdiarmid, F. D. Dick, and S. J. Watt, "Hearing symptoms and audiometry in professional divers and offshore workers," Occupational Medicine, vol. 60, no. 1, pp. 36-42, 2010.

[16] W. E. Daniell, S. S. Swan, M. M. McDaniel, J. G. Stebbins, N. S. Seixas, and M. S. Morgan, "Noise exposure and hearing conservation practices in an industry with high incidence of workers' compensation claims for hearing loss," American Journal of Industrial Medicine, vol. 42, no. 4, pp. 309-317, 2002.

[17] A. H. Mehrparvar, S. J. Mirmohammadi, A. Ghoreyshi, A. Mollasadeghi, and Z. Loukzadeh, "High-frequency audiometry: a means for early diagnosis of noise-induced hearing loss," Noise and Health, vol. 13, no. 55, pp. 402-406, 2011.

[18] M. H. Baradarnfar, K. Karamifar, A. H. Mehrparvar et al., "Amplitude changes in otoacoustic emissions after exposure to industrial noise," Noise and Health, vol. 14, no. 56, pp. 28-31, 2012.

[19] F. E. Ologe, T. M. Akande, and T. G. Olajide, "Occupational noise exposure and sensorineural hearing loss among workers of a steel rolling mill," European Archives of Oto-Rhino-Laryngology, vol. 263, no. 7, pp. 618-621, 2006.

[20] T. C. Morata, A. C. Fiorini, F. M. Fischer et al., "Toluene-induced hearing loss among rotogravure printing workers," Scandinavian Journal of Work, Environment and Health, vol. 23, no. 4, pp. 289-298, 1997.

[21] S. K. Bhattacharya, S. R. Tripathi, and S. Kashyap, "A study of heat and noise problems in a drug and pharmaceutical firm in India," Industrial Health, vol. 28, no. 4, pp. 203-207, 1990.

[22] G. H. Shaikh, "Noise problem in a polyester fiber plant in Pakistan," Industrial Health, vol. 34, no. 4, pp. 427-431, 1996.

[23] American National Standards Institute, Specifications for Audiometers. ANSI S3. 6-2004, American National Standard Institute, New York, NY, USA, 2004.

[24] US Department of Labor (USDL), "Occupational safety and exposure, hearing conservation amendment; final rule," Federal Register, vol. 48, pp. 9738-9785, 2009.

[25] R. Neitzel and N. Seixas, "The effectiveness of hearing protection among construction workers," Journal of Occupational and Environmental Hygiene, vol. 2, no. 4, pp. 227-238, 2005. 
[26] J. Edelson, R. Neitzel, H. Meischke et al., "Predictors of hearing protection use in construction workers," Annals of Occupational Hygiene, vol. 53, no. 6, pp. 605-615, 2009.

[27] S. C. Griffin, R. Neitzel, W. E. Daniell, and N. S. Seixas, "Indicators of hearing protection use: self-report and researcher observation," Journal of Occupational and Environmental Hygiene, vol. 6, no. 10, pp. 639-647, 2009.

[28] N. S. Seixas, B. Goldman, L. Sheppard, R. Neitzel, S. Norton, and S. G. Kujawa, "Prospective noise induced changes to hearing among construction industry apprentices," Occupational and Environmental Medicine, vol. 62, no. 5, pp. 309-317, 2005.

[29] H. Davies, S. Marion, and K. Teschke, "The impact of hearing conservation programs on incidence of noise-induced hearing loss in Canadian workers," American Journal of Industrial Medicine, vol. 51, no. 12, pp. 923-931, 2008.

[30] P. M. Rabinowitz, D. Galusha, C. Dixon-Ernst, M. D. Slade, and M. R. Cullen, "Do ambient noise exposure levels predict hearing loss in a modern industrial cohort?" Occupational and Environmental Medicine, vol. 64, no. 1, pp. 53-59, 2007.

[31] R. L. Neitzel, B. Stover, and N. S. Seixas, "Longitudinal assessment of noise exposure in a cohort of construction workers," Annals of Occupational Hygiene, vol. 55, no. 8, pp. 906-916, 2011.

[32] H. O. Ahmed, J. H. Dennis, O. Badran et al., "Occupational noise exposure and hearing loss of workers in two plants in eastern Saudi Arabia," Annals of Occupational Hygiene, vol. 45, no. 5, pp. 371-380, 2001.

[33] A. Osibogun, I. A. Igweze, and L. O. Adeniran, "Noise-induced hearing loss among textile workers in Lagos metropolis," The Nigerian Postgraduate Medical Journal, vol. 7, no. 3, pp. 104-111, 2000.

[34] F. M. Shakhatreh, K. J. Abdul-Baqi, and M. M. Turk, "Hearing loss in a textile factory," Saudi Medical Journal, vol. 21, no. 1, pp. 58-60, 2000.

[35] J. Jhonson and S. T. Robinson, "Occupational hearing loss," in Current Occupational and Environmental Medicine, J. Ladou, Ed., pp. 104-110, McGraw-Hill, New York, NY, USA, 3rd edition, 2007.

[36] M. E. Marvel, D. S. Pratt, L. H. Marvel, M. Regan, and J. J. May, "Occupational hearing loss in New York dairy farmers," American Journal of Industrial Medicine, vol. 20, no. 4, pp. 517531, 1991.

[37] T. Pirila, K. Jounio-Ervasti, and M. Sorri, "Left-right asymmetries in hearing threshold levels in three age groups of a random population," Audiology, vol. 31, no. 3, pp. 150-161, 1992.

[38] T. H. Simpson, D. McDonald, and M. Stewart, "Factors affecting laterality of standard threshold shift in occupational hearing conservation programs," Ear and Hearing, vol. 14, no. 5, pp. 322331, 1993.

[39] A. H. Suter, Hearing Conservation Manual, Council for Accreditation in Occupational Hearing Conservation, Milwaukee, WI, USA, 4th edition, 2002. 


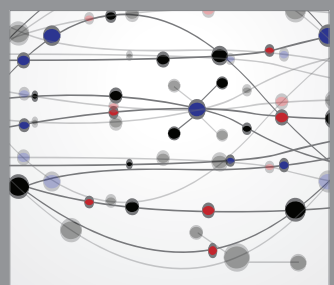

The Scientific World Journal
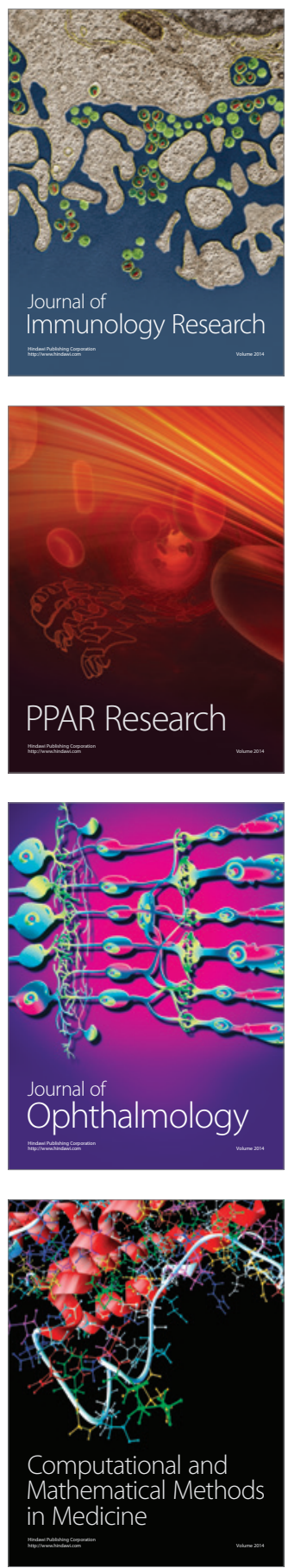

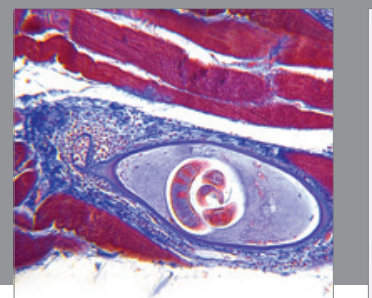

Gastroenterology

Research and Practice
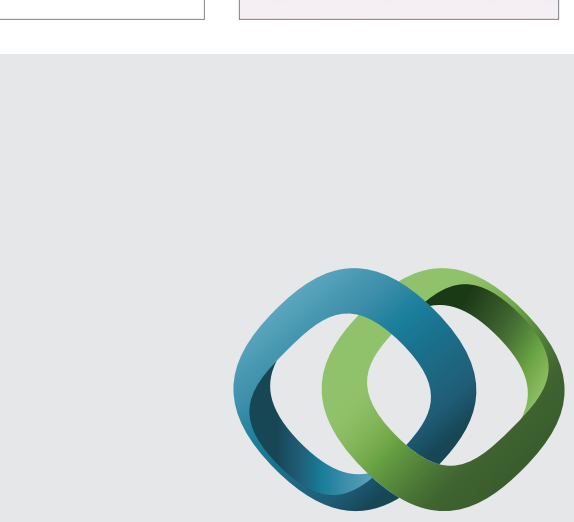

\section{Hindawi}

Submit your manuscripts at

http://www.hindawi.com
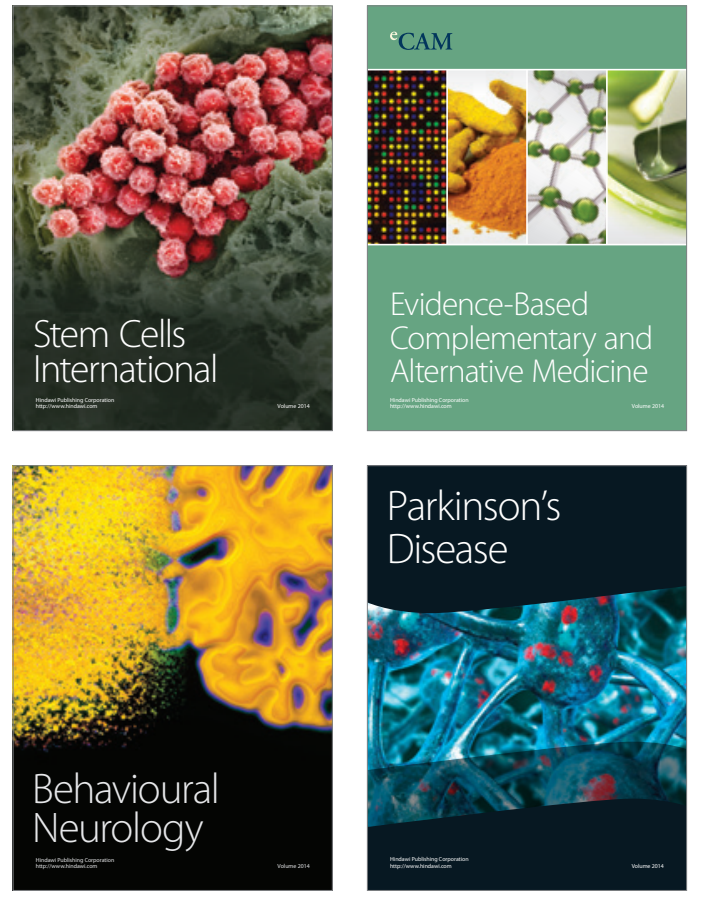
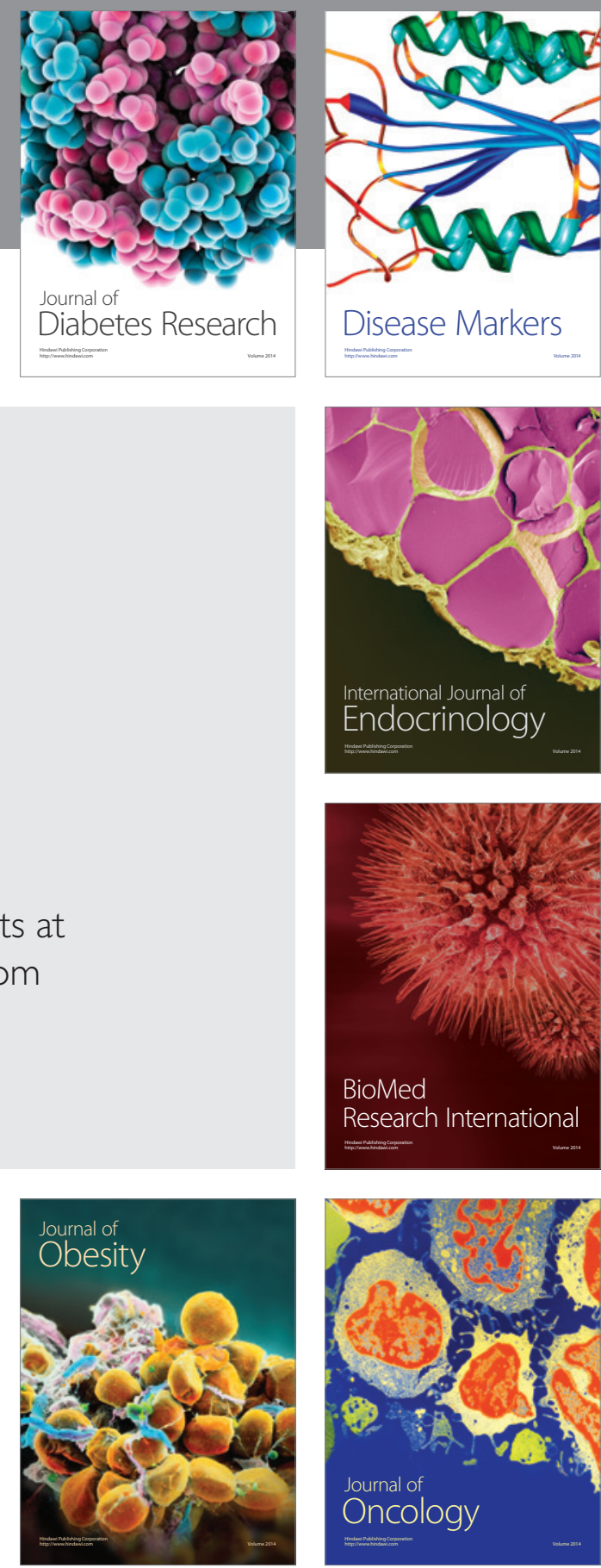

Disease Markers
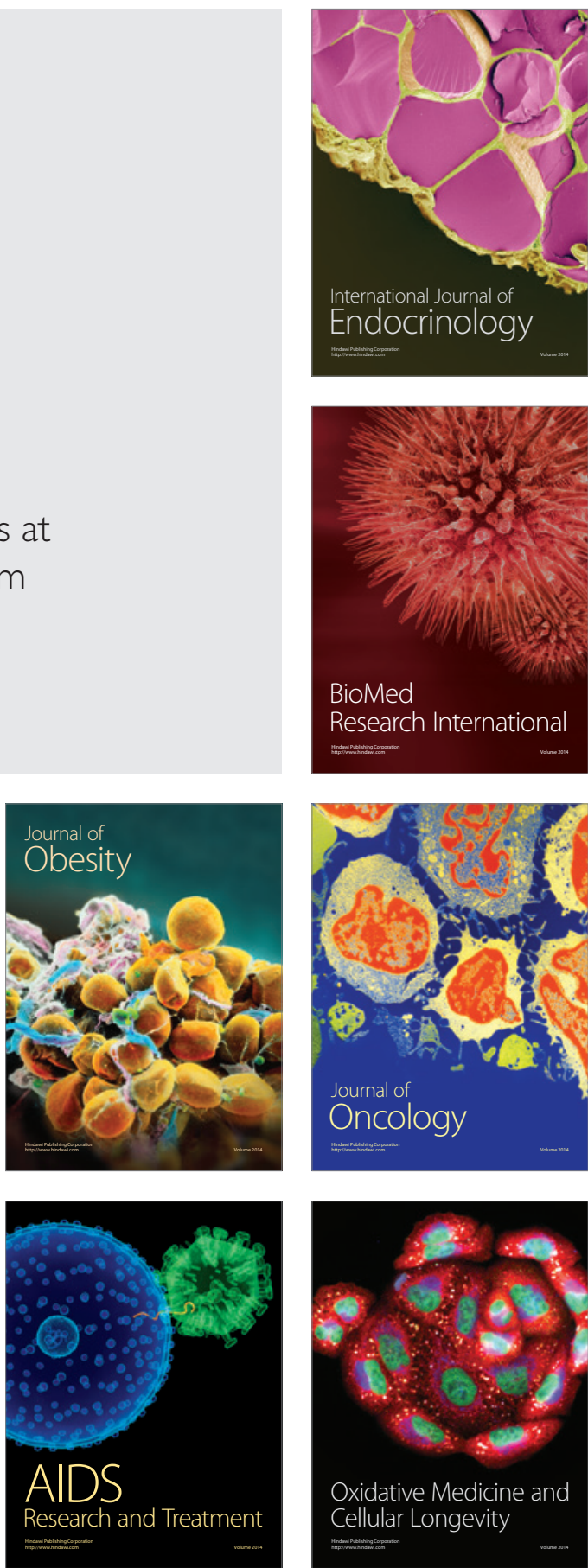